\title{
The Simple Problem of Financing Universal Health Care
}

\section{Jeffrey E. Jarrett ${ }^{*}$}

Department of Management Science and Finance, University of Rhode Island, USA

Many years ago when I worked for the agency that later became the Health Care Financing Administration, we found that universal health care was within our sight. The problem was to find an acceptable way to include all Americans in the plan without giving any extraordinary power to individual health care providers. The original plans for universal care became cannon fodder for the various economic powers within the health care provider communities. Each wished to reward themselves with extreme economic power to exact monopolistic returns for their services. All the providers and including the third party payers provided legislation for congress to act on to guarantee Americans health care. No matter how the system would work and be funded the goal was to provide health care services to all American citizens.

About forty years later, health care reform as we know it, will provide more health care services to more Americans than ever before. However, the products and services provided will not be uniform from state to state and the ultimate health care consumer will have choices to make with limited and perhaps very little information on how the individual programs will operate. Furthermore, to attract enough votes in Congress to pass the reform legislation, a government provider was eliminated from the possibilities of providing a plan. This so-called reform eliminates one form of competition for providers which may or may not produce the most efficient method for the distribution of health care products and services. By now, we see that the system will provide more affordable health care to more of our citizens than ever before. What we may lose is the most economically efficient program and the possibility of ever increasing revenues going to the health care providers who are not most efficient but most powerful. In a sense, some providers may be able to exercise monopolistic power resulting in higher process for their services. Much debate occurred on the role of provision of prescription drugs to health care consumers.

The price elasticity of health insurance is very high and consumers find it difficult to find coverage on their own. Health care reform is designed to solves this problem for eligible Americans through the implementation of income-based subsidies 'A question to be answered in the future will be whether these subsidies from state to state result in providing affordable care to every citizen through their separately chosen heal care provider. Regardless of these difficulties, the insurance exchanges established in each state will provide for a great reduction in the number of citizens who are uninsured. Furthermore, it is necessary for all to acquire insurance or pay a penalty in order for the system to work. The ability to "opt out" will create a possibility for the demolishing of the system from within. We do not expect this but only through fact gathering and statistical collection and analysis will we be able to ascertain whether the goals of health care reform are met.

By reforming and delivering health care in this way, insurers can no longer deny services to many who have been uninsured before because of their previous medical record. We need not go over the same ground walked before by those who believe health insurance is a luxury to be afforded $t$ by only a wealthy portion of the population. I blink when I previously heard arguments by many who could conclude that health insurance for all is not needed in this nation because the free market solves all problems of scarce goods.

With the implementation of the health care reform, we will have a better system for the provision of high quality health services to the great majority of United Sates citizens. However, leakages within the economic system for health care distribution may cause problems not heretofore discussed. In the future, we must study the system and based upon evidenced based research reform the system to make certain that the provision of health care is efficient and not subject to those who may profit from market inefficiencies resulting from poor planning, the lack of regulation and the insistence that any government action or program is inherently wrong. Women's reproductive health programs should be greatly improved by the financing systems developed in the health care reform.
*Corresponding author: Jeffrey E. Jarrett, Department of Management Science and Finance, University of Rhode Island, USA, Tel: 1-401-8744169; Fax 1-401-874-4312; E-mail: jejarrett@mail.uri.edu

Received June 21, 2013; Accepted June 25, 2013; Published July 01, 2013

Citation: Jarrett JE (2013) The Simple Problem of Financing Universal Health Care. J Bus \& Fin Aff 2: e126. doi:10.4172/2167-0234.1000e126

Copyright: (c) 2013 Jarrett JE. This is an open-access article distributed under the terms of the Creative Commons Attribution License, which permits unrestricted use, distribution, and reproduction in any medium, provided the original author and source are credited. 